\title{
In vitro evaluation of decontamination effects on mechanical properties of fibrin membrane
}

\author{
Taher Akbari Saeed ${ }^{1}$, Meysam Ahmadi ZeydAbadi ${ }^{2}$, Ahmad Fatemi $^{3}$, Alireza Farsinejad*4
}

\begin{abstract}
Background: Tissue engineering has been investigated as a potential method for healing traumatized tissues. Biomaterials are material devices or implants used to repair or replace native body tissues and organs. The present study was conducted to evaluate the effects of decontamination methods on biological/mechanical properties and degradation/adhesion test of the platelet?-rich fibrin (PRF) membranes to compare these properties with intact membranes as a biological biomaterial.

Methods: The in vitro degradation tests were conducted by placing the equal sizes of (i) intact PRF membrane, (ii) PRF membrane sterilized by autoclave (iii), ultraviolet (UV), and (iiii) gamma irradiation in phosphate buffer solution on a shaker. The degradation profiles were expressed. Adhesion test was performed by counting adhered mouse fibroblast and sterilized fibrin membrane was compared to normal fibrin membrane by different sterilization methods.

Results: The preliminary findings of sterilized PRF membranes showed that UV exposure $(p<0.05)$ and autoclaved fibrin membranes $(p<0.01)$ have significantly lower degradability compared to normal fibrin membranes. Gamma irradiation is similar to normal membrane in degradability. Cell adherence in all groups of fibrin membrane was significantly lower than the group without membrane, but there was no significant difference between intact and sterilized groups of fibrin membranes.

Conclusion: Sterilization of fibrin membrane with different protocols does not have any adverse effects on cell adhesion; however, cell adherence is naturally very weak even in normal membranes. Also, it seems that ultraviolet ray polymerizes fibrin filaments and merges them to each other and increases the ability of fibrin membrane against degradation. Autoclaved fibrin membrane content proteins are denatured because of pressure and heat and show an increase in hardness and stability against degradation.
\end{abstract}

Keywords: Fibrin, Tissue, Membrane, Mechanical phenomena, Biological phenomena, Decontamination

Copyright $₫$ Iran University of Medical Sciences

Cite this article as: Akbari Saeed T, Ahmadi ZeydAbadi M, Fatemi A, Farsinejad A. In vitro evaluation of decontamination effects on mechanical properties of fibrin membrane. Med J Islam Repub Iran. 2018(2 Feb);32:2. https://doi.org/10.14196/mjiri.32.2

\section{Introduction}

The amazing potential of living tissues for auto-regeneration may be restricted or impaired by an age-related droplet in the number and quality of host stem cell/progenitor populations by the naturally low regenerative capacity of certain tissues or by the negative effect of inflammation on wound repair (1). In an effort to recompense for such poor healing capacity, tissue engineering has been recognized as a potential therapeutic option to reform some of the biological processes that occur during tissue expansion and in the natural wound healing cascade in microcosms (2-4). For this purpose, harmonious combinations of scaffold/sup-

Corresponding author: Dr Alireza Farsinejad, farsinezhad239@yahoo.com

1.. Student Research Committee, Department of Medical Laboratory Sciences, Faculty of Sirjan Medical Sciences, Kerman University of Medical Sciences, Kerman, Iran.

2. Neuroscience Research Center, Institute of Neuropharmacology, Kerman University of Medical Sciences, Kerman, Iran.

3. Department of Hematology and Blood Bank, Faculty of Allied Medicine, Kerman University of Medical Sciences, Kerman, Iran.

4. Department of Hematology and Laboratory Sciences, Faculty of Allied medicine, Kerman University of Medical Sciences, Kerman, Iran. porting materials, sufficient target cells, and growth-stimulating bioactive factors are used to stimulate the rejuvenation of damaged tissues or to replace failing or malfunctioning/deteriorating organs (5). Biomaterials can be defined as material devices or transplants used to repair or replace native body tissues or as scaffolding materials adopted to construct manmade tissues and organs (6). Commonly, therapeutic biomaterials can be classified into 2 main groups: (I) living or once living material of animal or human origin, and (II) other materials including materials from vegetal sources, synthetic materials, and their compounds that are biocompatible and can be applied for tissue

$\uparrow$ What is "already known" in this topic:

One of the main reasons to avoid using this biomaterial as an allogeneic graft is the high probability of bacterial and viral infection transmissions. Sterilization is an important part in the preparation of biological materials for transplantation.

$\rightarrow$ What this article adds:

Sterilization of fibrin membrane with different protocols does not have any adverse effects on cell adhesion; however, cell adherence is naturally very weak even in normal membranes. 
regeneration. For over 2 decades, advancement in polymer science and tissue engineering has paved the way for the generation of sophisticated and ingenious biomaterials to optimize existing clinical treatments and develop more safe and effective cures for a higher quality of human life. The basic role of biomaterials in tissue engineering is to provide temporary mechanical support and mass transport to boost cell adhesion, proliferation, and differentiation and also control the size and shape of the regenerated tissue (7). Moreover, biomaterials, usually described as scaffolds, may present physical and chemical signals with spatiotemporal accuracy, which are of great importance in the modulation of cell performance and function and in the guidance of correct tissue rejuvenation, as an ECM contains the inherent signals pivotal to communicate with and control niche cells (8). Natural biomaterials present a vital subset of biomaterials for use as tissue engineering patterns due to their bioactivity, biocompatibility, tunable degradation, and mechanical kinetics, and their intrinsic structural resemblance of native tissue ECM. Natural biopolymers are often processed using environmentally-friendly aqueous-based methods. Upon application within biological systems, they do not release cytotoxic products during degradation, and their degradation rates may be adjusted by changing the starting formulation and/or processing situations (9). The use of synthetic polymers as matrices and templates in bioengineering presents several key advantages relative to naturally derived polymers and presents attractive options to control the shape, architecture, and chemistry to generate sensible alternatives or mimics of ECM systems of human origin that emulate or control biomaterial functions (10, 11). The most widely used synthetic polymers for tissue regeneration are poly $\alpha$-hydroxy acids, which include polylactic acid (PLA), polyglycolic acid (PGA) and their copolymers, and poly lactic-co-glycolic acid (PLGA) (12, 13).

Tissue engineering has been investigated as a potential method for healing traumatized tissues (14). A broad spectrum of biological and synthetic materials are used for the purpose of hastening wound healing, lowering pain, and serving as physiological barrier to decrease losses of water, minerals, and proteins through open wound surfaces (15, 16). Many tissue engineering strategies used in vitro cellscaffold composites are formed in bioreactor systems and later used for in vivo transplantation (17). A recent novelty in the field of medicine is the development of autologous platelet- rich fibrin (PRF) as a biological biomaterial (18). Platelet-rich fibrin (PRF) is a second-generation platelet concentrate (natural autologous fibrin matrix) that was first described by Choukroun et al. in 2000 (18-23). Fibrin is the triggered form of a plasmatic molecule called fibrinogen. This soluble fibrillary molecule is massively present both in plasma and in the platelet $\alpha$-granules and plays a determining role in platelet aggregation during hemostasis (18). It regulates inflammation and stimulates chemotactic factors in the immune response (20). PRF contains a considerable quantity of fibrins, platelets, and leukocytes and secretes 3 proinflammatory cytokines (interleukin-1b, interleukin 6 , and tumor necrosis factor- a), an anti-inflamma- tory cytokine (interleukin-4), and a key promoter of angiogenesis (vascular endothelial growth factor) (18). PRF also hastens angiogenesis, the multiplication of fibroblasts and osteoblasts, and cicatrization (21). In recent years, PRF has been used as an autologous grafting material because of its ability to accelerate physiologic wound healing and new bone formation. Several studies have evaluated the effectiveness of PRF in intra- bony and mandibular grade II defects and have found a positive clinical and radiographic result $(18,24-27)$. The routine use of such an inexpensive, autologous growth factor delivery system certainly offers an attractive option for the treatment of horizontal defects. One of the main reasons to avoid using this biomaterial as an allogeneic graft is the high possibility of bacterial and viral infection transmissions. Sterilization is an important part of the preparation of biological material for transplantation. To increase the safety of biological materials for transplantation, an important step following their preparation is sterilization to prevent the transfer of infectious diseases. Sterilization is supposed to eradicate all living microorganisms including bacterial spores and offer the sterility assurance level (SAL) of $10^{-6}(16,28,29)$. This can be reached by exposure of the tissue transplants to physical factors, such as hot air, saturated water vapors, ionizing radiation, plasma, or chemical substances (peracetic acid, ethylene oxide, glutaraldehyde, formaldehyde, etc.) (28, 29). The aim of our study was to measure the effect of some types of sterilization methods, such as gamma irradiation, ultraviolet (UV) and autoclave on biological and mechanical properties of fibrin membranes. To avoid the toxicity of the used chemicals, it seems more suitable to use sterilization by irradiation. This was used for the first time and patented in 1921 for the purpose of sterilization (30). Beta, gamma, and X-rays may be used, but gamma rays are preferred because of their excellent penetrance into biological scaffold, no increase of temperature, no harmful residues, decrease of the antigenicity of biological scaffold, and little biological and mechanical changes (31). Thanks to gamma rays penetrance, the biological scaffold can be sterilized in the packages, removing repeated microbial contamination (32). The most common sources of gamma rays are cobalt (60Co) or cesium (137Cs). The internationally suggested dose for sterilization of medical devices is $25 \mathrm{kGy}(33,34)$. For sterilization of biological scaffold, it is recommended to estimate the bioburden of the biological scaffold first, and then, according to its result, calculate the suitable irradiation dose assuring SAL $10^{-6}$. The main effect of irradiation is ionization of water molecules with formation of $\mathrm{H} 3 \mathrm{O}$ and $\mathrm{OH}-$. Hydroxyl radicals seriously damage the DNA of microorganisms and have strong oxidative effects as well. Bacterial spores are more resistant because of their low water content (35). Less sensitive to gamma radiation are also prions and some viruses, the concentration of which will be at routinely used dose of $25 \mathrm{kGy}$ only reduced (15). The sensitivity of pathogens to gamma radiation may be modified by several factors, such as temperature, presence of oxygen, and water. For example, elimination of HIV in deeply frozen plasma $\left(-80 \_\right.$C) is effective by irradiation with the dose of 50-100 kGy, which on the other hand, leads to de- 
naturation of collagen fibers in tissues $(15,36)$. Cell connection and proliferation rate significantly varies depending on biomaterial characteristics, influencing intercellular communications. Substitution and repair of injured tissue are to be made by biomaterials whose properties such as biocompatibility, nontoxicity, and numerous biomechanical ones have to meet the requirements of a defect to be repaired. On the other hand, mechanical properties similar to those of natural tissues are also necessary $(37,38)$. Good adhesion of the neighboring cells with the biomaterial surface to establish a hard connection in the implant-tissue interlayer is a prerequisite for successful repair. Good degradability is one of the other key properties of a biomaterial in tissue engineering.

\section{Methods}

This study was conducted at the Stem Cell Research Center in the Department of Hematology, Faculty of Medicine, Kerman University of Medical Sciences in 2016 and 2017. This study was conducted in 5 steps as follows:

\section{Preparation of platelet--rich fibrin}

After obtaining consent, a $10 \mathrm{~mL}$ blood sample was obtained intraoperatively from volunteers. An expert collected the blood, in most cases from the external jugular vein ( $\mathrm{n} Z 23)$, the femoral vein ( $\mathrm{Z}$ Z 6), or the distal vein ( $\mathrm{Z} 4$ ). Blood was collected into a sterile plain glass tube (BD Vacutainer Z; Becton, Dickinson and Company, Franklin Lane. NJ. USA; reference: 368430 ) and immediately centrifuged at $3000 \mathrm{rpm}(400 \mathrm{~g})$ for 10 minutes. The success of this technique depended on the swiftness of blood collection and transfer to the centrifuge. After centrifugation, a fibrin clot formed in the middle of the tube between the acellular plasma at the top and the red blood cells at the bottom. The clot was extracted from the tube, separated from red blood cells, and gently compressed between the 2 surgical swabs to have a soft and resistant membrane, which is usually approximately $>10 \mathrm{~mm}$ long and $<1 \mathrm{~mm}$ thick (Fig. 1). The entire procedure was performed under strict aseptic conditions.

\section{Sterilization}

We used 3 different types of sterilization methods for decontamination of our biological biomaterial. We divided our fibrin membranes in 4 groups as follow: 1 control group (not sterilized), and 3 groups sterilized by gamma radiation at $25 \mathrm{kGy}$ delivered by commercial 60 Co irradiation source, autoclave, and ultraviolet ray.

\section{Gamma radiation}

All fibrin membranes of gamma irradiation group were sent to the blood transfusion center of Kerman in Kerman, Iran. Gamma rays were emitted from cobalt- 60 radioactive source, with the dose rate of $23.04 \mathrm{~Gy} / \mathrm{min}$. The samples were irradiated at $25 \mathrm{kGy}$ by Gammacell ${ }^{\circledR} 3000$. Dosimetry was performed with ceric/cerous sulphate solution and measured using potentiometric method of analysis.

\section{Ultraviolet ray}

All fibrin membranes of UV group were exposed to UV ray that was emitted from UV light of cell culture hood (VRAYTM SUS UV Lamp System) for 30 (UV1 group) and 60 (UV2 group) minutes.

\section{Autoclave}

All fibrin membranes of autoclave group were sterilized at $121^{\circ} \mathrm{C}\left(249^{\circ} \mathrm{F}\right)$ for around 15 to 20 minutes and a pressure of approximately 15 psi (Reyhan Teb. 25L).

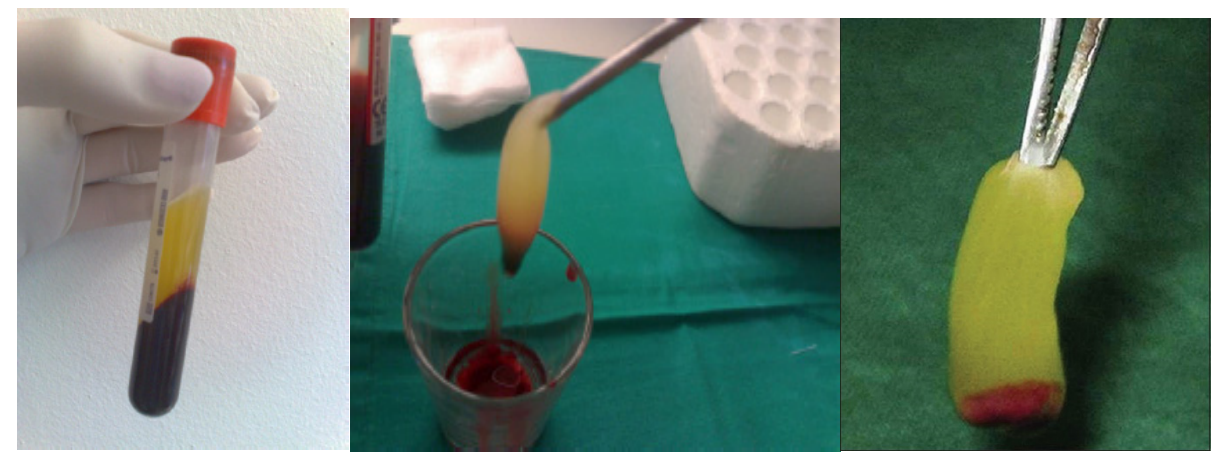

A: Centrifuged blood sample clot $\quad$ B: Coagulated serum separation $\quad$ C: Coagulated serum separation

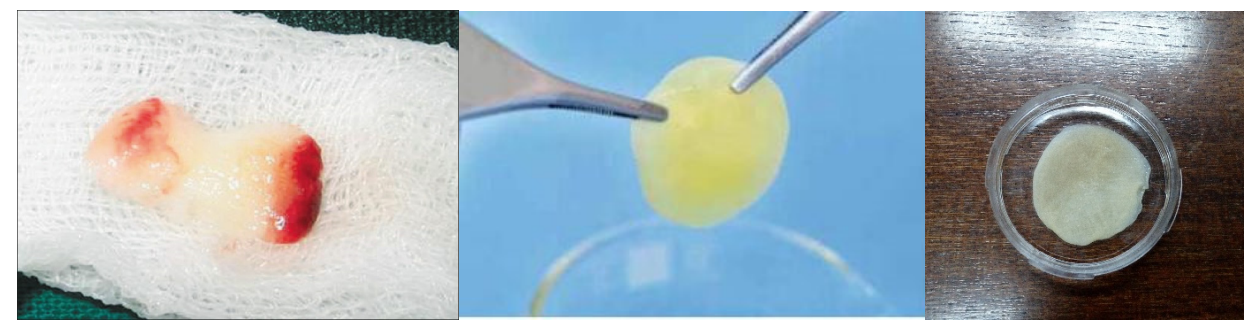

D: Compression of coagulated serum E: Washing prepared Fibrin membrane F: The final fibrin membrane

Fig. 1. Procedure of fibrin membrane preparations 


\section{Cell culture}

The 3T3-immortalized mouse fibroblast cell line was obtained from the pastor institute (Tehran, Iran) and used to study the substrate properties of sterilized fibrin membrane. $\mathrm{T}$

h

e

c

e

1

1

W

e

e

\section{In vitro degradation}

c The in vitro degradation tests of the sterilized membranes were conducted by placing the PRF membranes of size 20 k $10 \mathrm{~mm}$ in $10 \mathrm{~mL}$ of $\mathrm{pH} 7.4 \mathrm{PBS}$ on a shaker set (Orbital KAHN Shaker, Lab Line Instruments, Kochi, Kerala, India) at $40 \mathrm{rpm}$. We placed 3 fibrin membranes separately on the same shaker set from each 4 experimental groups to aompare the in vitro degradation profiles. All the 3 membranes were weighed on an electronic micro weighing scale; and at the end of 10 days, the membranes were taken dut of the incubation medium, washed with distilled water, dried, and their weight were measured. The degradation profiles were expressed as the accumulated weight losses of the membranes.

\section{Adhesion test}

: To evaluate the cell adhesion properties of each different sterilized fibrin membrane, a single cell suspension of mouse fibroblast cells was seeded onto the fibrin memBrane. All membranes of the 4 groups were placed in an Mcubator at $37^{\circ} \mathrm{C}$ for 2 different lengths of time: 60 minutes End overnight. Briefly, mouse fibroblast cells were incuBated at $37^{\circ} \mathrm{C}$ for 1 hour with 1.2 IU dispase and then trypsinized at $37^{\circ} \mathrm{C}$ for 30 minutes. The resultant single cell Stspension of fibroblast cells was then seeded onto each fiBrin membrane matrix spread on the bottom of culture in留rts $\left(5 * 10^{4}\right.$ cells/six well culture insert, $\left.\mathrm{N} 1 \frac{1}{4} 5\right)$. After incubation, non-adherent cells were washed with the culture fnedium (defined fibroblast growth medium (DMEM) supplemented with $10 \% \mathrm{FBS}$ ); then, the adherent cells were Frypsinized, and the cell number was then counted. In our series, we confirmed both macroscopically and histologiEally that no cells remained attached to the 4 different types of fibrin membranes (39).

$\mathrm{m}$ After data collection, all data were analyzed by IBM SPSS Statistics 23 software and t test. Moreover, p-value Pess than 0.05 with 1 star, less than 0.01 with 2 stars, and less than 0.001 with 3 stars was considered significant. $\mathrm{u}$

$\mathrm{m}_{\text {Results }}$

In vitro degradation
The PRF membrane was found to have maintained its physical form for up to 6 days, however, at the end of 10 days, the membrane showed a considerable amount of degradation. This degradation in group of gamma and normal fibrin membranes was high compared to UV exposed and autoclaved membranes. Mean weight loss percentage between start of the test day and the end of test in group of normal fibrin membranes was $1.3326 \pm 0.0777$ percent. In the group of fibrin membranes that was sterilized by UV1, UV2, autoclave, and gamma, the mean weight loss percentage between start of the test day and the end of test was $0.7625 \pm 0.083, \quad 0.7344 \pm 0.087, \quad 0.7033 \pm 0.0702$ and $1.018 \pm 0.108$ percent, respectively (Graph 1).

\section{Adhesion test}

The adhesion property of UV1, UV2, autoclave, gamma, and normal fibrin membranes was evaluated by incubating mouse fibroblast cells in 2 different lengths of time: 60 minutes and overnight. In the groups of 60- minute incubation, we could not find any evidence of cellular adhesions to the fibrin membranes. For the overnight incubation, the percentage of adherent cells on UV1, UV2, autoclave,

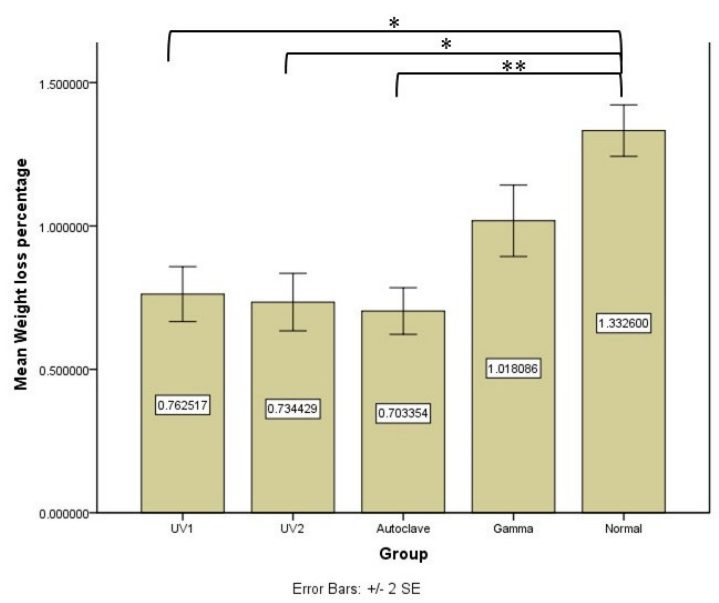

Graph 1. Results of 10- day degradation test of intact platelet-rich fibrin membranes and sterilized fibrin membranes $(*: \mathrm{p}<0.05, * *$ : $\mathrm{p}<0.01, * * *: \mathrm{p}<0.001)$

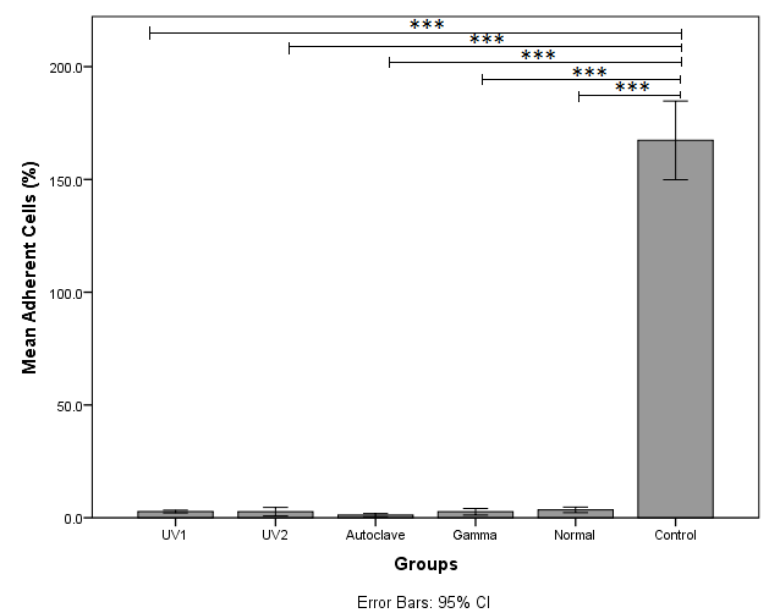

Graph 2. Results of adhesion test of intact platelet-rich fibrin membranes and sterilized fibrin membranes $(*: \mathrm{p}<0.05, * *: \mathrm{p}<0.01, * * *$ : $\mathrm{p}<0.001)$ 
gamma, and normal fibrin membranes was $2.7 \pm 6.77$, $2.6 \pm 7.78,1.1 \pm 7.28,2.6 \pm 7.09$ and $3.5 \pm 6.82$, respectively (Graph 2). These findings indicated that the adhesion property of all groups of fibrin membranes was very poor even though not sterilized and intact. The reason for this finding can be the physical and chemical nature of this biomaterial.

\section{Discussion}

The presented study evaluated appropriate sterilization methods and their impact on mechanical, biological, and cell culture properties in comparison to untreated fibrin membranes, as a further step towards the use of allogeneic fibrin membranes in animal studies and clinical application of this biological biomaterial.

Biomaterials of tissue engineering technology can provide a carrier for cell seeding and are expected to become an effective method for the regeneration and repair of tissues (40). The study by Murphy et al. (41) evaluated engineering fibrin hydrogels to promote the wound healing potential of mesenchymal stem cell spheroids and they found that fibrin hydrogels could be formulated with appropriate biophysical properties to simultaneously promote the proangiogenic and anti-inflammatory potential of entrapped MSC spheroids (41). Biological materials used for transplantation purposes should be sterilized before use, unless they are procured and processed by aseptic techniques. Sterilization methods should aim at preserving their original tissue structure as much as possible. Since the beginning of the 20th century, there have been attempts to develop an optimal way of tissue processing that could lead to development of a whole spectrum of sterilization methods (32). Approaches that included increased temperature proved to be unsuitable for treatment of biological materials. The best accepted method is the sterilization of allografts with gamma irradiation, which does not change the biomechanical properties of the tissue. In their study, Rediguieri et al. (42), evaluated the effect of ozone gas sterilization on the properties and cell compatibility of electrospun polycaprolactone scaffolds and found that the sterilization process successfully sterilized the scaffolds and preserved most of their initial attributes, except for mechanical properties. Although the scaffolds became weaker after sterilization, they were still robust enough to be used as tissue engineering scaffolds. This treatment increased the proliferation of L929 fibroblasts while maintaining cell viability, suggesting that ozone gas treatment may be a suitable technique for the sterilization of polymer scaffolds, which are significantly damaged by other methods (42). Rooney et al. (43) evaluated deeply frozen skin allografts mounted in 4 different concentrations of glycerol (20, 50 a $85 \%$ ), with consequent irradiation with the dose of $25 \mathrm{kGy}$ gamma rays. All specimens were kept at the temperature of $-80^{\circ} \mathrm{C}$, except for the one in $85 \%$ glycerol that was irradiated at the temperature between $30^{\circ}$ to $40^{\circ} \mathrm{C}$. Only the deep frozen tissue specimens mounted in $20 \%$ glycerol remained without histological, cytotoxic, or physical changes (43). The dose of $25 \mathrm{kGy}$ gamma irradiation seems to be a suitable sterilization method to decontaminate the tissue structures, as it does not have any negative effect on fibrin and elastic fibers of the biological biomaterial and is bacteriostatic.

The rationale behind the use of PRF membrane lies in the fact that the platelet $\alpha$ granules are a reservoir of many GFs that play a crucial role in hard and soft tissue repair mechanisms, which include platelet?derived GFs, transforming GF? $\beta$, vascular endothelial GF, and epidermal GF (44). PRF has to be considered as a fibrin biomaterial, and its molecular structure with low thrombin concentration is an optimal matrix for migration of endothelial cells and fibroblasts. Moreover, it permits a rapid angiogenesis and an easier remodeling of fibrin in a more resistant connective tissue $(19,45)$ Choukroun et al. were among the pioneers of using PRF protocol in oral and maxillofacial surgery to improve bone healing in implant dentistry (22). Several studies have examined the effectiveness of PRF in intrabony defects and grade II furcation defects and have found positive clinical and radiographic outcomes (18, 20-23, 4649). The addition of PRF as a membrane to coronally advanced flap showed an increase in the width of keratinized gingiva (50-55). PRF is a reservoir of soluble growth factors and cytokines (transforming growth factor beta-1, insulin-like growth factor 1 and 2, platelet-derived growth factor, cytokine vascular endothelial growth factor, and interleukin 1, 4, and 6) and not only helps in tissue regeneration but also accelerates wound healing. Studies have shown that PRF, when used with coronally advanced flap for recession coverage, decreases matrix metalloproteinase-8 (MMP-8) and interleukin beta levels but increases the tissue inhibitor of MMP-1 levels in 10 days, and thereby promoting periodontal wound healing in the earlier phase of the process $(56,57)$. In view of these positive findings, there is a need to extend the usefulness of PRF membrane to GTR applications as well. If we present a method to avoid bacterial and viral infection transmission during the use of this useful biological biomaterial as an allogeneic tissue graft, we can take an important step in this regard. The assessment of the mechanical and biological properties of PRF membrane for GTR procedures is required before its clinical use.

In this study, the modulus of elasticity and hardness of intact fibrin membrane were compared with the sterilized type of this biomaterial; and it was found that the modulus of elasticity and hardness was less for normal and gamma irradiated fibrin membranes compared to UV ray exposed and autoclaved membranes. This is because UV exposed and autoclaved fibrin membranes strands are denatured and polymerized, respectively, due to heat and UV ray, and their resistance increases in comparison to normal and gamma irradiated fibrin membranes. However, further research is needed to find a way to improve the adherence of fibrin membranes to cells. To have an effective biomaterial, adherent cells should be strongly connected to the biomaterial and use of the fibrin membranes as a growing media. However, the structural integrity of the implanted bio absorbable barrier membrane should be preserved for a sufficient time to ensure desired results. It seems that the reason for weak adherence between mouse fibroblasts and fibrin membrane is the instable linkage between them. Moreover, special characteristics and properties of the surface of 
this biomaterial is the main reason behind the loose adherence of fibrin membrane to the cells. The membrane degradation test results showed that PRF membrane was comparable to other sterilized membranes in maintaining its physical property up to 6 days. At the end of the 10 days, PRF membrane was found to have degraded significantly compared to initial weight and normal membrane. However, between these 4 groups, normal membranes had the most degradation and autoclaved membrane had the least degradation. Nonetheless, these results cannot be extrapolated with clinical data because the resorption process could be further facilitated by enzyme digestion in real applications. Future studies should be conducted to determine the actual degradation of PRF membrane in actual clinical conditions to obtain more clinically useful data.

Further in vitro and in vivo studies are needed to evaluate the mechanical properties and improve the rigidity of PRF membrane. The degradation profile of PRF membrane in vivo should also be assessed to find the exact time that PRF membrane maintains its structural integrity to act as an effective barrier membrane.

\section{Conclusion}

The ease of preparation and cost? effectiveness of PRF membrane offer a huge advantage over other commercially available membranes, especially in state of allogeneic use. The preliminary findings from the assessment of PRF mechanical properties and its comparison with other sterilized membranes do not offer promising results. Lack of rigidity and faster degradation may limit its application in GTR procedures. PRF can be considered a healing biomaterial that can be utilized in regenerative surgical procedures to fasten healing, but its application as a barrier membrane is doubtful due to its poor adherence properties. Allogeneic use of fibrin membrane without the threat of infection transmission can help conserve and produce fibrin membrane as a ready to use biological biomaterial with advantageous of inducing proliferation and differentiation. Allogenic PRF membrane may offer a promise in the field of periodontal regeneration if it meets the requirements and diversities of tissue regeneration procedures by improving its mechanical properties.

\section{Conflict of Interests}

The authors declare that they have no competing interests.

\section{References}

1. Place ES, Evans ND, Stevens MM. Complexity in biomaterials for tissue engineering. Nat Mater. 2009;8(6):457-70.

2. Feinberg AW. Engineered tissue grafts: opportunities and challenges in regenerative medicine. Wiley interdisciplinary reviews Systems biology and medicine. 2012;4(2):207-20.

3. Mikos AG, Herring SW, Ochareon P, Elisseeff J, Lu HH, Kandel R, et al. Engineering complex tissues. Tissue Eng. 2006;12(12):3307-39.

4. Langer R, Vacanti JP. Tissue engineering. Science. 1993;260(5110):920-6.

5. Harrison RH, St-Pierre JP, Stevens MM. Tissue engineering and regenerative medicine: a year in review. Tissue engineering Part B, Reviews. 2014;20(1):1-16.

6. Hanker JS, Giammara BL. Biomaterials and biomedical devices. Science. 1988;242(4880):885-92.
7. Hollister SJ. Porous scaffold design for tissue engineering. Nat Mater. 2005;4(7):518-24.

8. Dutta RC, Dutta AK. Cell-interactive 3D-scaffold; advances and applications. Biotechnol Adv. 2009;27(4):334-9.

9. Stoppel WL, Ghezzi CE, McNamara SL, Black LD, 3rd, Kaplan DL. Clinical applications of naturally derived biopolymer-based scaffolds for regenerative medicine. Ann Biomed Eng. 2015;43(3):657-80.

10. Seal B, Otero T, Panitch A. Polymeric biomaterials for tissue and organ regeneration. Materials Science and Engineering: R: Reports. 2001;34(4):147-230.

11. Lutolf MP, Hubbell JA. Synthetic biomaterials as instructive extracellular microenvironments for morphogenesis in tissue engineering. Nature biotechnology. 2005;23(1):47-55.

12. Pan Z, Ding J. Poly(lactide-co-glycolide) porous scaffolds for tissue engineering and regenerative medicine. Interface focus. 2012;2(3):36677.

13. Okamoto M, John B. Synthetic biopolymer nanocomposites for tissue engineering scaffolds. Progress in Polymer Science. 2013;38(10):1487503 .

14. Mardones R, Jofre CM, Minguell JJ. Cell Therapy and Tissue Engineering Approaches for Cartilage Repair and/or Regeneration. International journal of stem cells. 2015;8(1):48-53.

15. Ge Y, Feng H, Wang L. Application of a novel resorbable membrane in the treatment of calvarial defects in rats. Journal of biomaterials science Polymer edition. 2011;22(18):2417-29.

16. Mrazova H, Koller J, Fujerikova G, Babal P. Structural changes of skin and amnion grafts for transplantation purposes following different doses of irradiation. Cell Tissue Bank. 2014;15(3):429-33.

17. Lim JY, Donahue HJ. Biomaterial characteristics important to skeletal tissue engineering. Journal of musculoskeletal \& neuronal interactions. 2004;4(4):396-8.

18. Dohan DM, Choukroun J, Diss A, Dohan SL, Dohan AJ, Mouhyi J, et al. Platelet-rich fibrin (PRF): a second-generation platelet concentrate. Part I: technological concepts and evolution. Oral surgery, oral medicine, oral pathology, oral radiology, and endodontics. 2006;101(3):e37-44.

19. Soydan SS, Uckan S. Management of bisphosphonate-related osteonecrosis of the jaw with a platelet-rich fibrin membrane: technical report. Journal of oral and maxillofacial surgery : official journal of the American Association of Oral and Maxillofacial Surgeons. 2014;72(2):322-6.

20. Dohan DM, Choukroun J, Diss A, Dohan SL, Dohan AJJ, Mouhyi J, et al. Platelet-rich fibrin (PRF): A second-generation platelet concentrate. Part II: Platelet-related biologic features. Oral Surgery, Oral Medicine, Oral Pathology, Oral Radiology, and Endodontology. 2006;101(3):e45-e50.

21. Dohan DM, Choukroun J, Diss A, Dohan SL, Dohan AJ, Mouhyi J, et al. Platelet-rich fibrin (PRF): a second-generation platelet concentrate. Part III: leucocyte activation: a new feature for platelet concentrates? Oral surgery, oral medicine, oral pathology, oral radiology, and endodontics. 2006;101(3):e51-5.

22. Choukroun J, Diss A, Simonpieri A, Girard MO, Schoeffler C, Dohan SL, et al. Platelet-rich fibrin (PRF): a second-generation platelet concentrate. Part V: histologic evaluations of PRF effects on bone allograft maturation in sinus lift. Oral surgery, oral medicine, oral pathology, oral radiology, and endodontics. 2006;101(3):299-303.

23. Choukroun J, Diss A, Simonpieri A, Girard MO, Schoeffler C, Dohan SL, et al. Platelet-rich fibrin (PRF): a second-generation platelet concentrate. Part IV: clinical effects on tissue healing. Oral surgery, oral medicine, oral pathology, oral radiology, and endodontics. 2006;101(3):e56-60.

24. Horch RE, Beier JP, Kneser U, Arkudas A. Successful human longterm application of in situ bone tissue engineering. J Cell Mol Med. 2014;18(7):1478-85.

25. Gassling V, Hedderich J, Acil Y, Purcz N, Wiltfang J, Douglas T. Comparison of platelet rich fibrin and collagen as osteoblast-seeded scaffolds for bone tissue engineering applications. Clin Oral Implants Res. 2013;24(3):320-8.

26. Steffens L, Wenger A, Stark GB, Finkenzeller G. In vivo engineering of a human vasculature for bone tissue engineering applications. J Cell Mol Med. 2009;13(9B):3380-6.

27. Cool SM, Kenny B, Wu A, Nurcombe V, Trau M, Cassady AI, et al. Poly(3-hydroxybutyrate-co-3-hydroxyvalerate) composite biomaterials for bone tissue regeneration: in vitro performance assessed by osteoblast proliferation, osteoclast adhesion and resorption, and 
macrophage proinflammatory response. Journal of biomedical materials research Part A. 2007;82(3):599-610.

28. Matthews IP, Gibson C, Samuel AH. Sterilisation of implantable devices. Clinical materials. 1994;15(3):191-215.

29. Mrázová H, Koller J, Fujeríková G, Babál P. Structural changes of skin and amnion grafts for transplantation purposes following different doses of irradiation. Cell and Tissue Banking. 2014;15(3):429-33.

30. Boyd C. E-beam sterilizes the industry. J Stud Res. 2002;1:39-43.

31. Bolgiani A, editor Ittadiated allodermis as bed for cultured grafts. Book of Abstract of Sterilisation of Tissues using Ionising Radiations Conference; 2003.

32. Bourroul SC, Herson MR, Pino E, Mathor MB. Sterilization of skin allografts by ionizing radiation. Cellular and molecular Biology. 2002;48(7):803-8

33. Ab Hamid SS, Zahari NK, Yusof N, Hassan A. Scanning electron microscopic assessment on surface morphology of preserved human amniotic membrane after gamma sterilisation. Cell Tissue Bank. 2014;15(1):15-24.

34. Binte Atique F, Ahmed KT, Asaduzzaman SM, Hasan KN. Effects of gamma irradiation on bacterial microflora associated with human amniotic membrane. BioMed research international. 2013;2013:586561.

35. Berk F, Özer A. Radyasyonla sterilizasyon tıbbi aletlerde kullanımı. FABAD J Pharm Sci. 1999;24:223-31.

36. Hiemstra H, Tersmette M, Vos A, Over J, Berkel M, Bree H. Inactivation of human immunodeficiency virus by gamma radiation and its effect on plasma and coagulation factors. Transfusion. 1991;31(1):32-9.

37. Suchanek W, Yoshimura M. Processing and properties of hydroxyapatite-based biomaterials for use as hard tissue replacement implants. Journal of Materials Research. 1998;13(01):94-117.

38. Ignjatovic N, Suljovrujic E, Budinski-Simendic J, Krakovsky I, Uskokovic D. Evaluation of hot-pressed hydroxyapatite/poly-L-lactide composite biomaterial characteristics. Journal of biomedical materials research Part B, Applied biomaterials. 2004;71(2):284-94.

39. Freshney RI. Culture of Animal Cells: A Manual of Basic Technique and Specialized Applications: Wiley; 2011.

40. Yue W, Yan F, Zhang YL, Liu SL, Hou SP, Mao GC, et al. Differentiation of Rat Bone Marrow Mesenchymal Stem Cells Into Neuron-Like Cells In Vitro and Co-Cultured with Biological Scaffold as Transplantation Carrier. Medical science monitor : international medical journal of experimental and clinical research. 2016;22:176672 .

41. Murphy KC, Whitehead J, Zhou D, Ho SS, Leach JK. Engineering fibrin hydrogels to promote the wound healing potential of mesenchymal stem cell spheroids. Acta biomaterialia. 2017.

42. Rediguieri CF, De Bank PA, Zanin MHA, Leo P, Cerize NNP, de Oliveira AM, et al. The effect of ozone gas sterilization on the properties and cell compatibility of electrospun polycaprolactone scaffolds. Journal of biomaterials science Polymer edition. 2017;28(16):1918-34.

43. Rooney P, Eagle M, Hogg P, Lomas R, Kearney J. Sterilisation of skin allograft with gamma irradiation. Burns. 2008;34(5):664-73.

44. Sam G, Vadakkekuttical RJ, Amol NV. In vitro evaluation of mechanical properties of platelet-rich fibrin membrane and scanning electron microscopic examination of its surface characteristics. Journal of Indian Society of Periodontology. 2015;19(1):32-6.

45. Nagaveni NB, Kumari KN, Poornima P, Reddy V. Management of an endo-perio lesion in an immature tooth using autologous platelet-rich fibrin: a case report. Journal of the Indian Society of Pedodontics and Preventive Dentistry. 2015;33(1):69-73.

46. Dohan Ehrenfest DM, Andia I, Zumstein MA, Zhang CQ, Pinto NR, Bielecki T. Classification of platelet concentrates (Platelet-Rich Plasma-PRP, Platelet-Rich Fibrin-PRF) for topical and infiltrative use in orthopedic and sports medicine: current consensus, clinical implications and perspectives. Muscles Ligaments and tendons journal. 2014;4(1):3-9.

47. He L, Lin Y, Hu X, Zhang Y, Wu H. A comparative study of plateletrich fibrin (PRF) and platelet-rich plasma (PRP) on the effect of proliferation and differentiation of rat osteoblasts in vitro. Oral surgery, oral medicine, oral pathology, oral radiology, and endodontics. 2009;108(5):707-13.

48. Cieslik-Bielecka A, Choukroun J, Odin G, Dohan Ehrenfest DM. L$\mathrm{PRP} / \mathrm{L}-\mathrm{PRF}$ in esthetic plastic surgery, regenerative medicine of the skin and chronic wounds. Current pharmaceutical biotechnology. 2012;13(7):1266-77.
49. Braccini F, Tardivet L, Dohan Ehrenfest DM. [The relevance of Choukroun's Platelet-Rich Fibrin (PRF) during middle ear surgery: preliminary results]. Revue de laryngologie - otologie - rhinologie. 2009;130(3):175-80.

50. Tunaliota M, Ozdemir H, Arabaciota T, Gurbuzer B, Pikdoken L, Firatli E. Clinical evaluation of autologous platelet-rich fibrin in the treatment of multiple adjacent gingival recession defects: a 12-month study. The International journal of periodontics \& restorative dentistry. 2015;35(1):105-14.

51. Thamaraiselvan M, Elavarasu S, Thangakumaran S, Gadagi JS, Arthie T. Comparative clinical evaluation of coronally advanced flap with or without platelet rich fibrin membrane in the treatment of isolated gingival recession. Journal of Indian Society of Periodontology. 2015;19(1):66-71.

52. Del Corso M, Sammartino G, Dohan Ehrenfest DM. Re: "Clinical evaluation of a modified coronally advanced flap alone or in combination with a platelet-rich fibrin membrane for the treatment of adjacent multiple gingival recessions: a 6-month study". Journal of periodontology. 2009;80(11):1694-7; author reply 7-9.

53. Kassab MM, Cohen RE. Treatment of gingival recession. Journal of the American Dental Association. 2002;133(11):1499-506; quiz 540.

54. Cairo F, Pagliaro U, Nieri M. Treatment of gingival recession with coronally advanced flap procedures: a systematic review. Journal of clinical periodontology. 2008;35(8 Suppl):136-62.

55. Jankovic S, Aleksic Z, Klokkevold P, Lekovic V, Dimitrijevic B, Kenney EB, et al. Use of platelet-rich fibrin membrane following treatment of gingival recession: a randomized clinical trial. The International journal of periodontics \& restorative dentistry. 2012;32(2):e41-50

56. Femminella B, Iaconi MC, Di Tullio M, Romano L, Sinjari B, D'Arcangelo C, et al. Clinical Comparison of Platelet-Rich Fibrin and a Gelatin Sponge in the Management of Palatal Wounds After Epithelialized Free Gingival Graft Harvest: A Randomized Clinical Trial. Journal of periodontology. 2016;87(2):103-13.

57. Eren G, Tervahartiala T, Sorsa T, Atilla G. Cytokine (interleukin1beta) and MMP levels in gingival crevicular fluid after use of plateletrich fibrin or connective tissue graft in the treatment of localized gingival recessions. Journal of periodontal research. 2016;51(4):481-8. 